\title{
EDITORIAL
}

\section{Preface: special issue Hamao Umezawa (1914-1986)}

The Journal of Antibiotics (2018) 71, 1; doi:10.1038/ja.2017.136

\begin{abstract}
A globally recognized microbiologist, medical doctor, educator and leading multidisciplinary scientist and administrator, Prof Hamao Umezawa pioneered microbiology research and improvements in public health and welfare in Japan for four decades following the Second World War. His seminal work on microbial metabolites, drug resistance and rational drug design has had a profound and guiding influence on the development of microbial chemistry worldwide. His accomplishments, especially the discovery of kanamycin (discovered in 1957/marketed in 1958) and bekanamycin (kanamycin B, 1957/1969), proved especially significant resulting, in 1962, in him being presented with the Cultural Medal, one of Japan's most prestigious awards at the comparatively young age of 48 . In the same year, he established the Institute of Microbial Chemistry (IMC) in Tokyo, where influential basic and applied research on antibiotics has been undertaken continually ever since.

At IMC, many successful projects benefitted from his direction, including, the discovery of anti-bacterial compounds, such as kasugamycin (1965/1970) and josamycin (1967/1970); anti-cancer agents, such as bleomycin (1965/1969) and aclacinomycin (1975/1982); enzyme inhibitors, such as leupeptin (1969/1978) and pepstatin (1970/1975), all of which are microbial secondary metabolites. His rational drug development techniques led to the appearance of dibekacin (second generation of kanamycin B, 1971/1975) and arbekacin (third generation of kanamycin B, 1973/1990), which were designed to avoid the enzymatic inactivation of kanamycin B. The anti-cancer drugs peplomycin (second generation of bleomycin, 1978/1981) and pirarubicin (doxorubicin analog, 1979/1988) were semi-synthesized.
\end{abstract}

After his death in 1986, work to successfully combat drug-resistant bacteria and cancer has been driven forward by many who benefitted from his thinking, philosophy and training. In this special issue of the Journal of Antibiotics, we highlight some of those advancements, a particularly fitting tribute because more than $80 \%$ of his discoveries were published in this journal.

During the Hamao Umezawa era at IMC (1962-1986), numerous scientists from home and abroad visited the institute, discussed with him, were influenced by him, and some were fortunate to receive his direct guidance. Several of these friends and individuals have already passed away or retired but some remain, working on the discovery and refinement of antibiotics. More than 10, all leading scientists, have enthusiastically contributed toward honoring him in this special issue. As issue coordinators, each of us would like to thank them all deeply and sincerely for their contributions, and to add our voices in celebration to one of Japan's leading scientific and public health pioneers.

\section{CONFLICT OF INTEREST}

The authors declare no conflict of interest.

Kuniaki Tatsuta $^{1,2,3}$, Yoshikazu Takahashi ${ }^{2,4}$ and Manabu Kawada ${ }^{2,4}$

${ }^{1}$ Editor-in-Chief; ${ }^{2}$ Coordinator of the issue, The Journal of Antibiotics;

${ }^{3}$ Waseda University, Tokyo, Japan and ${ }^{4}$ Institute of Microbial Chemistry,

Tokyo, Japan

E-mail: tatsuta@waseda.jp 